\title{
Solving Ebola, HIV, Antibiotic Resistance And Other Challenges: The New Paradigm Of Probabilistic Innovation
}

Chris William Callaghan, University of the Witwatersrand, South Africa

\begin{abstract}
The global innovation pipeline that provides new drugs to counter threats like Ebola or totally drug resistant tuberculosis and bacteria has slowed; fewer drugs are being produced and higher levels of investment are yielding lower outputs. This paper argues that the innovation process that underlies proprietary, or profit-seeking, innovation faces an S-curve effect, which is reflected in diminishing returns to investment. A new S-curve is identified, in the form of second generation innovation (SGI) and second generation research and development (SGR). What SGI and SGR have in common is their use of probabilistic mechanisms of knowledge creation. Probabilistic mechanisms refer to the exposure of problem solving processes to very large numbers of problem solvers. An example of this is crowdsourced $R \& D$ and crowdsourced innovation contests. The overarching argument made in this paper is that many of the medical and social problems faced today can be solved by a more extensive use of processes associated with this new paradigm in innovation.
\end{abstract}

Keywords: Paradigm Of Drug Development; S-curve Effect; Probabilistic Mechanisms Of Knowledge Creation; Probabilistic Mechanisms

\section{INTRODUCTION}

ince the 1940s, antibiotics, or antimicrobial agents, have "greatly reduced illness and death from infectious diseases"; however, the resistance of these microbes to these drugs has increased, and they are no longer as effective (CDC, 2014:1). Antimicrobial resistance is a global concern because of its relationship with higher mortality rates, with decreasing control over infectious diseases, increasing health costs, its potential to jeopardise health care gains to society itself, and the negative effect it has on health security, trade and economies (WHO, 2014).

There are certain trends in drug resistance. Methicillin-resistant Staphylococcus aureus (MRSA), a dangerous staph bacteria, multidrug-resistant Gram-negative bacteria, multi-drug resistant strains of Klebsiella and Escherichia coli pose serious risks, particularly to hospital patients (CDC, 2014). Similarly, malaria parasites and other parasites are becoming increasingly tolerant to antimicrobial drugs, as has also been the case with drugs used to treat human immunodeficiency virus and fungal infections (CDC, 2014). In 2012, 450000 cases of multidrugresistant tuberculosis (MDR-TB) had already emerged, and extensively drug-resistant tuberculosis (XDR-TB) has been found in 92 countries across the world $(\mathrm{CDC}, 2014)$. Third generation cephalosporins have recently failed as a last line of defence against gonorrhoea according to reports from ten countries already; the disease is predicted to soon be untreatable as no vaccines or new drugs are in development (CDC, 2014). Resistance by bacteria, fungi, viruses and parasites to drugs is rapidly increasing; these trends are not limited to industrial countries but are occurring all over the world (CDC, 2014). The evolution of these resistant strains is particularly problematic because organisms have been found to be able to exchange resistant traits between themselves (CDC, 2014).

These trends are particularly concerning, given the emergence of new diseases, or new outbreaks of disease; an example of a new outbreak is the current spread of the virulent Ebola virus across countries in Africa, 
which the World Health Organisation has categorised as an international health emergency (Karimi \& Gigova, 2014). However, the world now faces a global crisis as drug development has slowed; the consequences of rising costs of technology development across the world have constrained the potential of closed models of innovation to solve problems (Chesbrough, 2007). Historically, research has suggested that the patents firms are developing are decreasing relative to their research and development (R\&D) investments over time (Hausman, Hall \& Griliches, 1984). This problem is particularly acute in pharmaceutical development, where investments required to produce successful products have experienced a ten-fold increase over the course of a decade (Chesbrough, 2007).

The shipping lives of new drugs under patent protection in the pharmaceutical industry have shortened, primarily because research and development $(\mathrm{R} \& \mathrm{D})$ testing procedures take longer and generics are increasingly available (Chesbrough, 2007). Similarly, makers of these drugs also face increasing competition within classes of drugs, and these challenges all make it more difficult for firms to justify investments in innovation (Chesbrough, 2007).

Notwithstanding these constraints to innovation (and therefore to new drug development), there are certain theoretical reasons for why innovation might have 'levelled off' in the pharmaceutical industry. One body of theory relates to the 'stickiness' of information and knowledge, and explains a fundamental constraint to innovation and knowledge creation. According to this body of literature, problem solving requires the necessary information and problem-solving capabilities to be brought together (von Hippel, 1994). However, the fundamental constraint to this process is that this information can be costly to obtain, and it can also be costly to transfer and to use in the new location, a characteristic that von Hippel (1994) dubs 'information stickiness'. Problems that need to draw on knowledge and information from different sites require some method to transcend these challenges; one approach is to partition tasks into sub-problems that can use one locus; another is to reduce the stickiness of knowledge and information at certain locations (von Hippel, 1994). Nonetheless, following von Hippel's (1994) theory, this paper argues that this problem of the stickiness of knowledge and information (von Hippel's notion of information is expanded here to include knowledge) poses a constraint to innovative knowledge production akin to a threshold limit. In much the same way that technologies and systems can over time produce less value, it is argued that the systems and processes associated with closed model innovation have reached their 'natural limit' (Foster, 1985), as the ' $S$ ' curve associated with closed model innovation, termed first generation innovation in this paper, reflects the inability of the system to produce new drugs. This constraint is conceptualised as an innovation 'threshold', or 'constraint threshold'. It is argued that the only way in which this constraint 'threshold' can be breached consistently is through the adoption of a probabilistic mechanism of knowledge creation.

The core argument of this paper is therefore that the stickiness of knowledge (von Hippel, 1994) poses a constraint to innovation that cannot be breached without the use of probabilistic mechanisms that reconfigure the 'knowledge space' so as to change the location of information, the cost structure of its generation and its transfer across nodes of creation, and that improve the efficiencies with which it can be used in new locations. This paper therefore makes the argument that at the nexus of proprietary and social 'probabilistic R\&D, there exists the alignment of economic incentives with social goals, a 'space' in which problem solving can be accelerated significantly. Probabilistic mechanisms are taken to represent ways in which knowledge and information harness probabilistic forces through the exposure of problems to very large numbers of people (nodes of creation) for the purposes of problem solving. By increasing the numbers of problem solvers exponentially, the chances of solving problems may also be increased exponentially. The use of these probabilistic mechanisms is taken to represent a new paradigm in innovation, termed Second Generation Innovation (SGI). First Generation Innovation (FGI) is taken to represent the paradigm in innovation that does not utilise probabilistic mechanisms. Having briefly outlined the argument made in this paper, the structure of the paper is now considered.

This paper follows the precedent offered by other theoretical papers. It consists of certain arguments that are synthesised to provide predictions in the form of propositions which are testable. The rest of this paper proceeds as follows. First, the concept of second generation innovation is discussed in relation to the probabilistic threshold of innovation and three models derived from this body of theory, namely the Global Model, the Synthesis Model and a model of the multiplier process that is associated with non-proprietary innovation. Next, precedent for the use of SGI and SGR in the form of innovation contests is considered. After this, the technological context of advancement is discussed in order to provide an argument that the technology now exists to support SGI and SGR. A model is 
then presented, which illustrates the argument that at the nexus of social and proprietary (for profit) $R \& D$ is a space in which social goals are aligned with private incentives; and that this nexus can be increased in proportion to financial investment in an innovation process. The paper then concludes with an overview of the arguments made.

\section{Second Generation Innnovation Theory}

This paper builds on other work (Callaghan, 2014a) that argues that knowledge creation can be radically accelerated through the use of open source crowdsourced research and development (R\&D), in the form of SGR and SGI, which represent a new and more effective form of knowledge creation, a new paradigm in innovation that can offer much in the way of societal problem solving.

At the heart of this model is the notion that knowledge creation can be enabled probabilistically, or that knowledge creation can occur on such a large scale that knowledge can be created exponentially (Callaghan, 2014a). Crowdsourcing has provided a powerful impetus to the potential of the Web to support knowledge creation (Doan, Ramakrishnan \& Haley, 2011). It is possible that if organisations 'catch this wave' of change timeously, they may be able to use the processes associated with this new paradigm to solve problems in a way that makes a dramatic contribution to societal stakeholders. Callaghan (2014a) argues that first generation innovation and first generation $\mathrm{R} \& \mathrm{D}$ is unable to deliver the societal benefits required of a world that is experiencing declining returns to investment, particularly in the pharmaceutical innovation pipeline. The 'probabilistic threshold', illustrated in Figure 1 , represents the constraints to forms of innovation that do not use probabilistic mechanisms in their processes; in other words, FGI. Second generation research and development (SGR) is the process of research and development (R\&D) which is one of the stages of the innovation cycle, but one which utilises probabilistic mechanisms in its operation.

\section{The Probabilistic R\&D Space: Second Generation Innovation}

\section{The Probabilistic Threshold}

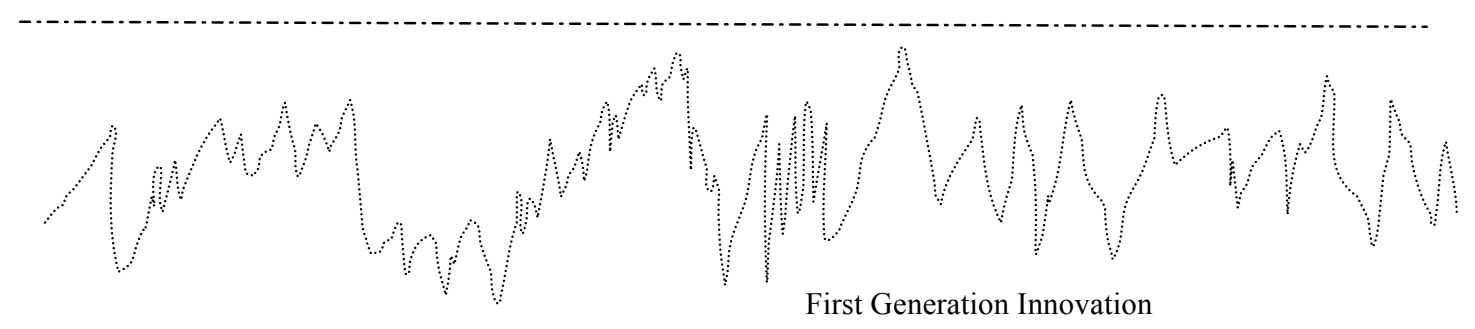

Figure 1: The Probabilistic Threshold Constraints Posed By The 'Stickiness' Of Information

There are certain implications that arise from this notion of a probabilistic threshold. One implication is that only a probabilistic process can overcome this threshold constraint. Other work has developed models that have been derived from this body of theory. Three examples of models derived from this growing body of literature exist, namely the Global Model, the Synthesis Model, and the multiplier effect. These are briefly considered as follows.

The 'Global Model' applies SGR to societal problem solving, with a special focus on crowdsourcing to direct information and knowledge inputs toward the solving of one particular global-scale problem at a time (Callaghan, 2014c). According to this model, if countries in the world were to pledge certain future health budget costs that relate to a particular problem, then a cumulative 'reward fund' could be pooled, that was large enough to enable crowdsourced R\&D or any form of R\&D to deliver a solution. For Callaghan (2014b):

The idea behind the Global Model is that if all 170 or so countries in the world (those that are able to) could pledge their yearly budgets for this problem for one year, five years in advance, then the reward would exist for a crowdfunded solution to the problem. The money would only need to be paid by countries if a solution was found; countries cannot lose because if no complete solution is found then nothing needs to be paid...If the solution is 
found, then countries gain the equivalent of the net present value of all spending that would have continued into the future until a cure or solution was found in another way.

Callaghan (2014b) extends this concept to the development of another model, the 'Synthesis Model', and explains this process as follows: "What is different, however, about the Synthesis Model is that it can account for its own genesis; a SGI project of this nature can use SGF [second generation fundraising processes] to 'seed' itself using the crowd, and SGR to capture information and knowledge value from the crowd...these SG processes can tap into, and make use of, probabilistic learning processes used in nature that have been extraordinarily successful for biological organisms and other forms of life, that also use these processes for "learning". According to Callaghan (2014b):

The Synthesis Model is premised on the notion that the entire innovation process can be 'unhinged', or 'decoupled' from FGI processes; so that the process is primarily based on the probabilistic paradigm offered by SGI, using both crowdfunding and crowdsourcing. This model is based on the notion that learning and problem solving using the crowd can increase its chances of success, or the probability of finding solutions, if the problem solving is spread across an extremely large number of potential solvers.

What differentiates the potential of this 'Synthesis Model' in terms of social versus proprietary innovation, however, is the notion of a 'multiplier effect', where feedback flows transcend dyadic mechanisms; in other words, when knowledge creation using crowdsourced R\&D processes is not constrained by the need to keep proprietary knowledge secret from the others in the crowd (Callaghan, 2014b).

The purpose of this paper is to extend this notion of SGI and SGR in relation to the tension between social and proprietary R\&D. The aim of the paper is therefore to develop these ideas in order to develop theoretical conceptions around the possibility of enabling breakthrough innovation in scientific endeavours. SGI theory has as its fundamental tenet the prediction that exposing problems to exponentially increased problem solving input may alter the odds of solving these problems in some sort of proportion to the increase in inputs. This can be loosely dubbed 'The Law of Reductability', the extreme form of it being that 'the solution to any problem that is ultimately solvable is a function of the quality and quantity of problem solving input it receives', or $S=f(I)$, where other variables in this relationship are considered to be exogenous to the problem solving function.

The implications of this law seem, at first glance, to be ridiculous. As implied by the Global Model, all that would be necessary to, for example, cure a disease, is to simply raise enough money and offer it as a reward. Could it be so simple? According to this law, it is. And it is this tension that this paper seeks to address. If SGI theory predicts that the solution to all serious societal problems (comprised of 'knowable' relationships) is simply a function of the input they can generate, then the real question becomes 'what are the boundary conditions to this theoretical prediction?' Other subordinate questions are: Under what conditions does this law hold, and what denotes a problem as 'ultimately solvable', or comprised of knowable relationships? This paper seeks to identify a specific 'locale', or 'space' which exists at the nexus of social SGR and proprietary SGR, in which the social objectives of innovation are aligned with private incentives. This model, termed the Nexus Model, offers a perspective of a 'nexus' space, which can be increased in proportion to the financial investments contributed toward the solving of a particular problem (which is inherently solvable).

For the purposes of this work, a problem is considered to be ultimately solvable if the state of its solution is a function of discrete processes that can be manipulated by problem solvers. This implies that knowledge itself falls into two categories: (i) what can be known (what is comprised of knowable relationships) and (ii) what cannot be known (what is comprised of 'unknowable' relationships). Finding a solution to curing a disease might be considered a function of permutations of processes that will yield multiple different sources of potential solutions. Finding a solution to time travel (to keep with the ridiculous) might fall into the latter category. However, in the absence of categorical knowledge of whether a solution might fall into either of these, the only way to find out might be to enable a large enough scale of investments of inputs into a problem solving process.

Aligning the incentive mechanisms to support the operationalisation of these models, however, seems to be a necessary condition for their success in producing innovations. If private, or proprietary, systems of innovation 
cannot be relied upon to deliver innovation, or to maintain a pipeline of societally important innovations, then alternative models of innovation are needed. One potential solution to this incentivisation problem is the use of online innovation contests (Hallerstede \& Bullinger, 2010). This is a rapidly developing field, albeit relatively new and small at present, but with unexplored potential for problem solving (Hallerstede \& Bullinger, 2010).

\section{Innovation Contests: An Example Of Open Probability-Based Innovation}

Innovation contests might be considered examples of open innovation that utilise the probabilistic mechanism of large-number problem solving, as problems are exposed to large numbers of problem solvers. Examples of innovation contexts in history abound. Napoleon III of France, for example, used an innovation contest to find a replacement for butter in 1869; from this, margarine emerged (Hallerstede \& Bullinger, 2010).

Hallerstede and Bullinger (2010) studied 65 innovation contests (web-based competitions of innovators who provide solutions to contest challenges) to understand how to categorise them. Hallerstede and Bullinger (2010) categorised innovation contests into three main clusters, or types, namely (i) community-based, which use social media and are typically aimed at community building and offer non-monetary rewards; (ii) expert-based, which use social media but are primarily aimed at providing solutions to explicitly specified tasks, including prototypes, which are evaluated by experts; and (iii) mob-based, which run for a long time, using limited social media, and either offer monetary or non-monetary rewards (but not mixed), with inputs that are moderately elaborated and are based on ideas. An example of a mob-based innovation contest is the Virgin Earth Challenge which requested contributors to provide a commercially viable design which would result in the removal of greenhouse gasses (Hallerstede \& Bullinger, 2010). Notably the levels of confidentiality rise from (i) to (ii) and further to (iii), and rarely do any of these forms use Wikis, discussion forums or tagging systems to discriminate between contributions, indicating perhaps that relatively little collaborative contributions occur (Hallerstede \& Bullinger, 2010). The lack of knowledge sharing that is associated with the need to keep inputs secret, however, constrains the knowledge creation process by keeping it dyadic in nature (Callaghan, 2014a). The community and mob-based types were found to be most appropriate when budget constraints exist, as they seem to motivate innovators through non-monetary rewards; this was not the case for expert-based types, which typically require higher levels of reward because of the more elaborate solutions or prototypes they seek (Hallerstede \& Bullinger, 2010). A differentiation is evident in the literature, which reflects a phenomenon whereby individuals contribute to open innovation for other motivations than those associated with remuneration. In order to place probability-based innovation as conceptualised in this paper in relation to the innovation literature in general, the first order of business is to place crowdsourced R\&D, or SGR, as a form of SGI, in relation to other forms of innovation. One way of doing this is to place SGR in relation to typologies of innovation.

\section{Placing Probability-Based Innovation In Relation To Typologies Of Innovation}

According to Pravitt's (1984) seminal typology, the characteristics of variations in innovations can be categorised according to whether the innovation is (i) supplier dominated; (ii) production intensive; or (iii) science based, and according to differences in sources of technology, the requirements of users, and possibilities for appropriation. For Pravitt (1984:343), this explanation of types of innovation "has implications for our understanding of the sources and directions of technical change, firms' diversification behaviour, the dynamic relationship between technology and industrial structure, and the formation of technological skills and advantages at the level of the firm, the region and the country." For Salter and Martin (2001), there is also a typology of the benefits from public investment in basic research, which varies by scientific field, technology and industrial sector. The importance of this typology relates to the need for state funding for basic research to take into account these differences, over and above the need for state funding to address market failure (Salter \& Martin, 2001). There are two rates of return to research: (i) private rates of return, or "return on investments in research that flow from an individual research project to the organisation directly involved", or social rates of return, which accrue to society in general (Salter \& Martin, 2001:514). It is argued here that at the nexus of social and proprietary probabilistic, or SG innovation is an 'innovation space' in which social goals are also aligned with private incentives. It is in this 'space' that breakthroughs might be significantly more likely. 
Historically, neoclassical models of technological change have considered the production of technology itself and innovations as exogenous and have not taken into consideration the diversity or variety inherent in the "sources, nature and uses of innovations" (Pravitt, 1984:343). For the purposes of this paper, innovation is defined as "a new or better product or production process", following Pravitt (1984:343), yet sans the requirement "successfully commercialised"; SGI is taken to represent any part of the innovation process that utilises a probabilistic process, or that utilises a mechanism through which the use of large numbers of inputs are incorporated. The notion "successfully diffused" is preferred, given that social innovation is the focus of the arguments made in this paper.

SGI potentially also encompasses a different conception of innovation; one that explores the potentialities associated with the relaxation of the knowledge management requirements associated with the need for proprietary control of knowledge, particularly in the three dimensional space of knowledge creation where the knowledge multiplier effect is enabled through these relaxations. The differentiation of SGI from FGI gives rise to another typology of innovations. Within this differentiation, a further differentiation can be taken to exist, between proprietary probabilistic innovation and social probabilistic innovation, the former associated with profit-seeking and the latter associated with outcomes that are pursued for social benefit yet not necessarily for profit. It is argued that at the nexus of these two types is an innovation 'space', within which both profit-seeking and socially oriented probabilistic innovation types are aligned in their goals and targeted outcomes. This 'space' is diagrammatically represented in Figure 2, which is discussed later.

Probabilistic mechanisms of SGI such as crowdsourcing are not without their pitfalls. These pitfalls might be considered to represent yet another typology. The following are examples of constraints to the use of crowdsourcing offered by Davenport, Cummings, Daellenbach and Campbell (2013:15): (i) project delays, because there is no guarantee that the crowd can provide the solutions or have the motivation to do so; (ii) low quality, as oftentimes contributors are not professionals and quality control might be absent from the process; (iii) ambiguous liability, which may mean that there is no accountability for poor quality work; (iv) the temporary relationships associated with crowdsourcing, which might lead to lower quality output; (v) the professionalism of internal employees or traditional contractors, which might be undermined; (vi) an identity clash might exist, as crowdsourcing winners' solutions might not fit with the culture of the organisation; (vii) exploitation and reputation effects might be problematic when low wages or no wages are used to exploit intellectual property with no contractual obligations, and ethical issues arise which can have reputational consequences; and (viii) losers in crowdsourcing can be discouraged and this can arouse negative attitudes towards the company or with the crowdsourcing initiative.

In such a relatively new field, the notion of typologies might be useful, because they may provide a framework against which the boundary conditions of theory and predictions can be mapped as the field progresses. Notwithstanding these typologies, there seem to be two dimensions along which innovation and problem solving in science can be accelerated. Firstly, this acceleration may occur through the enablement of technology in general and through the knowledge management potential of technology in particular. Secondly, this acceleration may occur through the exponential increase in knowledge that can result from connecting people together in a way that increases the probability of findings solutions to problems. Although the true potential of these dimensions may work optimally when combined, for the purposes of discussion within this paper these are now considered separately. In order to make arguments that relate to how people can use SGI and SGR, it is first necessary to offer a perspective of what support technology can provide to these processes.

\section{Reaching Critical Mass-Technological Knowledge Accumulation In Unsupervised Modes}

The acceleration of knowledge creation has been considered from different perspectives. Certain theorists have argued for the creation of self-supervised machine learning systems to create volumes of structured data, which then create opportunities of individuals to create applications (Wu \& Weld, 2007). This is useful because an information system would work best if it "autonomously extracts information from the Web", operating in an unsupervised or self-supervised mode (Wu \& Weld, 2007:41). These technologies seem uniquely placed to support SGI processes. 
The logic that underpins these processes is the knowledge redundancy that exists on the Web, providing enough variance in the language of items that simple versions of information can be picked up (Wu \& Weld, 2007). Nevertheless, incorrect information can also be picked up, and $\mathrm{Wu}$ and Weld (2007) propose a prototype system, termed 'KYLIN', which can autonomously extract structured data in a way that improves on the Wikipedia system in a way that reduces the challenges associated with collaboratively authored data which is typically associated with noise and incompleteness. This is just one example of probabilistic machine learning, which is perhaps analogous to the SGI and SGR processes, which relate to human learning.

Wu and Weld (2007) used Wikipedia as a basis for the development of their proposed prototype. Wikipedia can also be taken to offer insights that may contribute to the vision of crowdsourced R\&D. Wikipedia is therefore a useful example of a platform off which social crowdsourcing in the form of open R\&D can be launched to solve societally important scientific problems. The technology to support radical process innovations in the realm of crowdsourced R\&D seems to already exist. In fact, SGI and SGR are perhaps only practically possible because of these advances in technology.

Other work on the Semantic Web suggests that semantic mappings are needed between ontologies, and advances have been made that allow the taxonomic structures of ontologies, which increase the abilities of the Web to support learning on a large scale (Doan, Madhavan, Dhamankar, Domingos \& Halevy, 2003). The large scale of this 'artificial' learning, on a large or probabilistic scale, can be a complement to the human cognitive learning if the latter can be enabled on a similar scale. At the heart of any acceleration in knowledge creation, however, is the ability to capture knowledge and successes in a process model that is continually updated based on knowledge of prior successes and failures. The notion of an on-line process handbook is just one useful example of how this might be done.

The idea has been mooted of collecting examples of how processes are performed in different organisations and developing an on-line process handbook (Malone, Crowston, Lee, Pentland, Dellarocas, Wyner, Quimby, Osborn, Bernstein, Herman, Klein \& O'Donnell, 1999). In this way, others could redesign processes and develop new ones that can take advantages of the changes in technology, while providing insight at the different levels of abstraction and of the deep structure of the similarity between processes (Malone et al., 1999). Process innovations that 'catch on' can quickly become 'best practices', and information technology will continue to provide opportunities for more process innovations to continually emerge, but for "quicker progress on these problems, however, our best hope is to develop a more systematic theoretical and empirical foundation for understanding organizational processes" (Malone et al., 1999). A more comprehensive review of literature that specifically relates to technological processes related to second generation innovation is, however, beyond the scope of this work. This body of literature seems to suggest that technology has progressed to the point at which it might support SGI and SGR in the form of a new paradigm of scientific investigation. It is possible that the emergence of SGI and SGR is a natural extension of the trend toward open innovation itself, and that these represent an underlying process innovation that offers the potential of a new S-curve that will transcend FGR. However, it is the technology underlying the use of SGI and SGR that is perhaps driving this new paradigm, and that is inherently related to the emergence of a new S-curve in innovation as a field itself.

\section{The Trend Towards Open Innovation: Placing Second Generation Innovation In Relation To The Trajectory Of Change In Innovation Theory}

For Chesbrough (2007), innovation has been trending toward openness, or an open process, because of a growing division of labour. For example, a firm might have the competencies to develop a novel idea but bringing this idea to market might in turn require different competencies (Chesbrough, 2007). By opening business models, it is possible for firms to search for and exploit outside ideas and to allow unused internal technologies to flow 'to the outside', which allows their latent economic potential to be exploited (Chesbrough, 2007). It is perhaps at the nexus of (i) private models of innovation, that have turned to open innovation, and (ii) social models of innovation (notfor-profit, but for societal good) that have also turned to open innovation (in order to transcend the limitations of revenue generation), that the space for radical social innovation can occur. At this nexus, the objectives of each coincide- the goals of those involved in social innovation are also aligned with the incentives provided by profit- 
seeking innovation. Both social and proprietary innovation can take advantage of the platform provided by second generation innovation, and its model of open innovation.

Opening the business model itself offers a new 'frontier' in innovation, according to Chesbrough (2007). At the heart of this process of innovation, however, is the notion that these process are driven by a business model; a business model creates value (through a series of value-adding activities) and attempts to capture as much of this value as possible (through the development of a unique resource or process) that provides competitive advantage (Chesbrough, 2007). Open business models allow synergies with other firms to be exploited because different firms have different configurations of assets, resources and market positions, and new configurations might add value, which other firms might be more familiar with (Chesbrough, 2007). However, if innovations require business models to structure the creation of value and the capture of this value then it is more difficult to facilitate social innovation that cannot sustain a business model.

For Chesbrough (2007), the markets for innovation can be highly inefficient, as technology and its intellectual property exchanges are typically at the mercy of processes dominated by brokers and patent attorneys, and knowledge of prices and volumes of activity is obscured. The consequence of this is that value-adding trade and exchange in innovation does not happen due to high costs and a lack of knowledge; innovation therefore remains 'on the shelf' (Chesbrough, 2007). For Chesbrough (2007), firms may typically only use between $5-25 \%$ of their patents, while the rest remain dormant; which is becoming a more serious issue in a global context of a rising cost of technology development across many industries. This also has implications for social innovation, which requires a much higher rate of innovation than this in order to solve societal problems.

This problem is particularly acute in pharmaceutical development where investments in successful products have typically required a ten-fold increase over the course of a decade (Chesbrough, 2007). There is an implication that arises from this - that only large firms will get bigger, leaving others behind, while at the same shortening product life-cycles, the presence of generics and increasing competition within drug classes are creating economic pressures on innovation, or reducing the incentives firms have to invest in innovation (Chesbrough, 2007).

However, open innovation can address these challenges, through its influence on (i) the cost side, using external R\&D resources to achieve time and cost advantages, and (ii) the revenue side, by licensing technologies from other sources, or alternatively by licensing technologies to others (Chesbrough, 2007). Therefore, by opening business models up, the reduced costs of innovation and its potential benefits make innovation more attractive, notwithstanding the influence of shorter product life cycles (Chesbrough, 2007).

Firms should experiment with their business models, and create processes that enable this, but typically the incentives of managers at different levels of the organisation are not aligned with this type of process innovation, according to Chesbrough (2007). Companies like Google experiment, for example, using separate Web sites to elicit customer feedback, and spin-offs and start-ups can also be used to this end (Chesbrough, 2007). Gains have also been realised by companies like IBM who have changed their strategy from defensively keeping intellectual property secret to offensively licensing it to outside parties, including competitors, which has proved to offer profitability advantages (Chesbrough, 2007). In fact, IBM has been spending about $\$ 100$ million per year on developing Linux open source software for its own use, saving development costs by tapping into the potential of open innovation (Chesbrough, 2007).

The recognition of open source by IBM is reflected in its donation of over 500 of its software patents to the open source community, to develop the 'intellectual commons' of open source software (Chesbrough, 2007). Proctor and Gamble (P\&G) have also set up an R\&D strategy that sought to bring in half of its ideas externally, which has allowed them to increase their innovation capacity without an increase in costs (Chesbrough, 2007). Oftentimes, however, it takes a crisis to change the mindset of an organisation in cases where open innovation has been taken up as part of new business models, yet open innovation is necessary to increase the innovation capacity of organisations (Chesbrough, 2007).

For Chesbrough (2007) the shift to a more open model of innovation can be achieved by typically following two processes: (i) adjusting the business model to manage higher volume, while standardising or 
automating certain processes and (ii) obtaining 'buy in' from many important sectors within the company, as 'losers' are inevitably created as resources are re-channelled toward the new business model and resistance emerges. However, for many organisations the alternative to opening up business models might be business declines in many contexts (Chesbrough, 2007). A range of forces can be taken to be exerting an influence on businesses to increasingly take up open models of innovation, such as crowdsourcing.

Crowdsourcing has grown rapidly, with lobby-group support emerging (Finzen and Kinz, 2012). Crowdsourcing has been incorporated into business models more slowly in certain national contexts, for example in Germany (Finzen and Kinz, 2012). Diversity typically contributes to innovation, through the collaboration between universities, private firms, corporate research laboratories and public research institutes (Bienkowska, Larsen and Sörlin, 2010). The development of innovative capabilities for innovation clusters is also enabled by labour mobility (Bienkowska, Lundmark and Malmberg, 2011).

Certain countries such as China and India have scale advantages and bargaining power associated with their innovation and R\&D growth (Karabag, Tuncay-Celikel and Beggren, 2011). However, these advantages are not available to many developing countries, which require active private capital together with economies of scale in production and support from public policies in order to attract international R\&D (Karabag et al., 2011). The pattern of R\&D does not therefore entirely reflect path-dependent locational effects of human capital in the new global knowledge economy, and also does not reflect homogeneity (Karabag et al., 2011).

Pharmaceutical R\&D seems to locate globally based on agglomeration and cluster economies that provide a 'critical mass' in research; this tends to favour cites in the United States, Europe, Japan and China (Karabag et al., 2011). However, clinical development and testing is dependent on scale economies in patient numbers and networks of testing physicians and follow-up opportunities; the locational advantages of $R \& D$ versus clinical testing differ in their optimum location (Karabag et al., 2011). However, crowdsourced R\&D can offer independence from locational constraints.

An important question that has dominated the R\&D literature over time is whether public $R \& D$ is a complement ('adds to') or a substitute for ('crowds out') private R\&D (David, Hall \& Tool, 2000). Other research, however, has found an absence of crowding out, on either a full or partial basis, between public and private R\&D spending; and that certain firms in small or low technology sectors might not undertake R\&D if subsidies are not provided (González \& Pazó, 2008). Other studies have found that tax credits for R\&D can result in the creation of the same magnitude of additional R\&D (Hall \& Van Reenen, 2000). What this body of literature has in common is its consideration of constraints to $R \& D$, which can be surmounted to some extent through the use of second generation R\&D.

Examples of innovation contests abound in the literature. Napoleon III of France used one to discover margarine, a substitute for butter, and the Orteig Prize for the first nonstop flight between New York and Paris contributed to the emergence of the airline industry (Hallerstede \& Bullinger, 2010).

Terwiesch and $\mathrm{Xu}$ (2008) offer a typology of products and cost structures that are relatively more suited to using contests to stimulate innovation. For Terwiesch and Xu (2008:1529) the "detailed mechanics of R\&D differ widely by industry, reflecting different cost structures, different success rates, and different market rewards, but the innovation process is remarkably similar across industries" as drug "candidates in a pharmaceutical development process, TV shows in an entertainment company, and proposals in a venture capital firm all flow through a conceptually similar innovation process". Open innovation relies on altruism and the status needs of open source community members, or self-interest that is not primarily related to financial rewards; on the other hand, innovation contests offer explicit rewards for innovations (Terwiesch \& Xu, 2008).

In a context of off-shoring and outsourcing innovation, innovation contests have come of age as a basis for "solid R\&D problem solving in recent years" (Terwiesch \& Xu, 2008). InnoCentive is a firm that puts seekers together with solvers, to the tune of 95000 around the world, as scientific problems and the rules of the contest are communicated to this 'crowd' (Terwiesch \& Xu, 2008). If the solutions are acceptable, the seeker buys the intellectual property from the solver; common rewards range from $\$ 10000$ to $\$ 50000$ (Terwiesch \& Xu, 2008). 
Seekers benefit from this process because it generates competition between solvers, only successes are paid for (the incidence of failed investment in innovation falls to the solvers), a wide range of providers are available which increases the chances of problem solving, cost savings exist through wage arbitrage, and a higher level of idea generation and testing is enabled (Terwiesch \& $\mathrm{Xu}, 2008$ ).

However, there are certain problematic aspects of crowdsourced R\&D in the form of innovation contests, namely the potential for solvers to not be financially compensated for their efforts, which can lead to underinvestment and inefficiency in the market for solutions, unless the reward system is better aligned to address this (Terwiesch \& Xu, 2008). Terwiesch and Xu (2008) contest the notion that innovation contests optimise problem solving when limited to two contestants because of underinvestment effects that exist despite the fact that these parties still benefit from competition, arguing that diversity can have its own benefits that mitigate the negative influence of underinvestment. The efficiency of innovation contests can be increased if other mechanisms are used, over and above those that are dependent on performance; an example of this is multiround contests, where a first round includes large numbers of contestants with low levels of contributions, followed by a second round that includes only those that have shown potential, which would increase the chances of someone in this smaller pool being successful (thus reducing underinvestment) (Terwiesch \& Xu, 2008).

Open source software "allows users to design, build, distribute, and support their own programs- no manufacturer required"; this is part of a trend toward getting customers to be innovators (Thomke \& von Hippel, 2002). However, using customers to drive innovation requires an understanding of the differences between how value is created and captured in customer innovation models and the conventional models of innovation (Thomke \& von Hippel, 2002). At the heart of problems in product development is the fact that information about needs is typically in the hands of the customer and information about how to satisfy those needs is typically in the hands of manufacturers (Thomke \& von Hippel, 2002).

\section{THE NEXUS MODEL}

What is clear from this body of literature considered above is that open innovation, termed probabilistic innovation here, offers new opportunities for the acceleration of innovation, or for the acceleration of the potential yield of innovation applied to problem solving. A tension in this body of literature exists, however, in that the differentiation between social and for-profit innovation does not seem to be clearly addressed in this body of literature. It is argued here that at the nexus of private, or proprietary crowdsourced $R \& D$ and crowdsourced $R \& D$ that is targeted at achieving social goals, there is an area of overlap between these two activities.

In Figure 2, a model of crowdsourced R\&D at the junction of proprietary and non-proprietary innovation is shown. In this model, the innovation activity that occurs outside of the probability frontier is shown outside of the larger circle. This area outside of this circle represents first generation innovation. Within the outer circle are innovation activities that utilise some aspect of probabilistic innovation. The two circles within the larger one represent social, or non-proprietary probabilistic $\mathrm{R} \& \mathrm{D}$ (on the left) and proprietary probabilistic R\&D (on the right). The intersection between these represents crowdsourced $R \& D$ activities that have both a commercial payoff as well as a social benefit. It is argued that this nexus represents an area in which a critical mass of incentives can be found. It is within this area perhaps that there is the most likelihood of breakthroughs, or successful innovations, which may benefit society. 


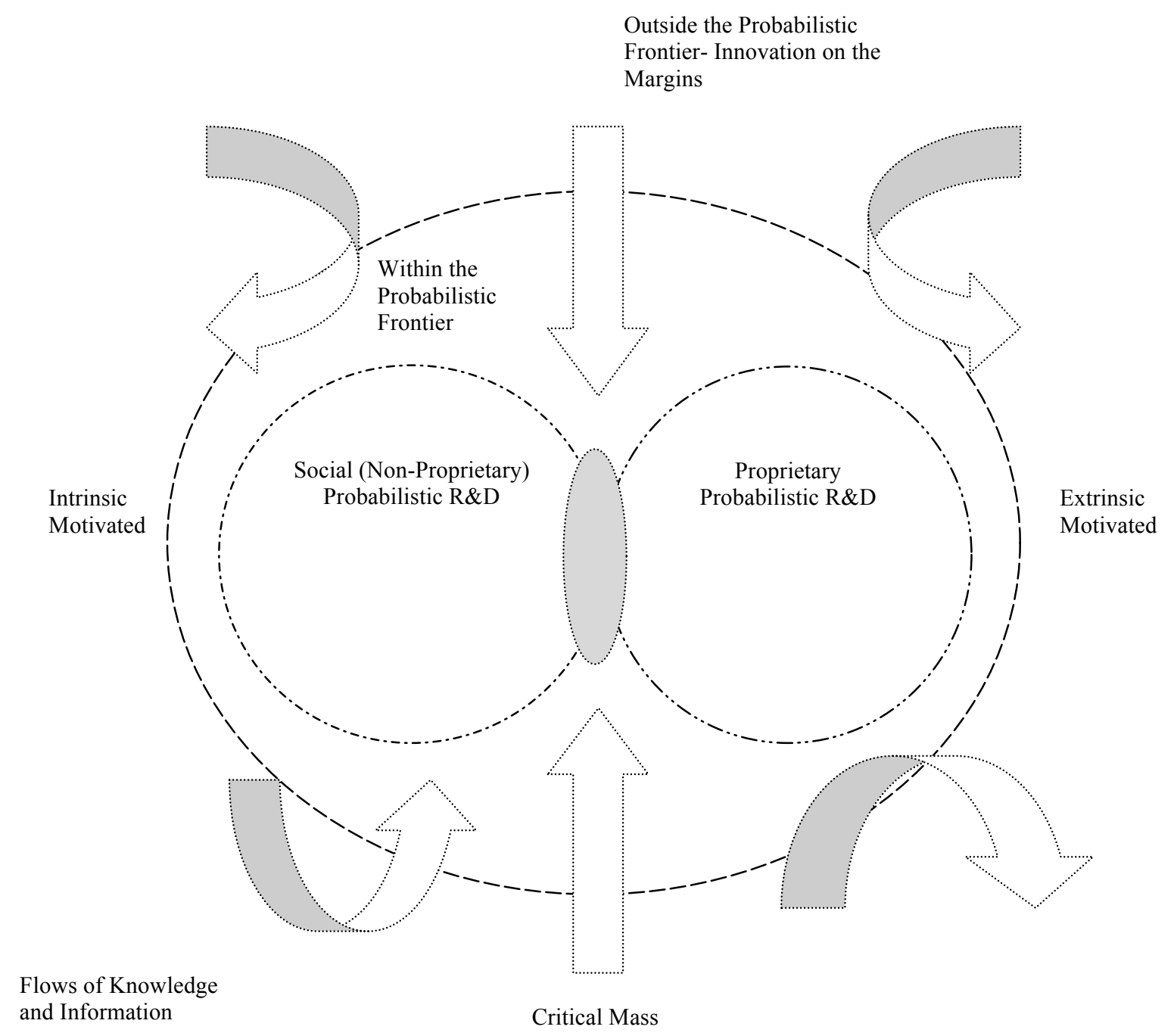

Figure 2: The Nexus Model, A Model Of The Crowdsourced R\&D Space At The Nexus Of Proprietary And Non-Proprietary Innovation

According to this model, where both societal goals and the goals of profit-seeking are aligned is an innovation 'space' which can vastly increase the probability of successful problem-solving. The implication of this model is that different types of innovation activity should perhaps be 'steered' toward this area where social and proprietary R\&D meet. In this area, a 'critical mass' might be reached, where incentives are aligned with social goals. It is argued here that if the proprietary incentives could be increased to a very high level, perhaps through the use of innovation contests, then such critical mass might be attained. An example of this process might be the use of pledged funds from countries around the world, which might enable a very large amount of money to be offered as a prize for an innovation contest to solve the problem of Ebola, or the problem of antibiotic or microbial resistance to pharmaceutical drugs. The Global Model (Callaghan, 2014a) suggests that breakthrough innovations with regard to healthcare could be achieved if the World Health Organisation were to oversee innovation contests on a global scale. Callaghan (2014a) suggests that if all countries in the world pledge their health budgets for a problem five years ahead of time it would cost the countries little if a solution was found; in this case the monies that they pay would be paid five years hence, and they would then gain the net present value of all outflows that would otherwise have arisen from this problem in years six, seven and so on. The Global Model (Callaghan, 2014) is an example of how social probabilistic $R \& D$ could occur in the same space as proprietary probabilistic $R \& D$. In this instance, the use of extremely large 'pledged' bodies of funds can be used to 'force' the nexus of these two different areas of R\&D. This 
'forced nexus' also represents the embodiment of intrinsic and extrinsic motivations on the part of those engaged in the probabilistic R\&D process. The intrinsic motivation associated with open source contributors is combined with the extrinsic (monetary) motivation of those working within proprietary systems of R\&D. The larger the incentive, the larger the area of the nexus between these two different forms of probabilistic R\&D might become.

On the basis of this model, and the discussions above, Proposition 1 is offered, that the higher the financial incentives provided for social probabilistic $R \& D$, the higher will be the overlap of intrinsic and extrinsic motivation on the part of contributors. Similarly, Proposition 2 is also derived, that the higher the financial incentives provided for social probabilistic $R \& D$, the greater the area of overlap between social and proprietary $R \& D$ in their problem solving efforts. On the basis of these two propositions, Proposition 3 is further derived, that using SGR almost any problem can be solved whatsoever, the only constraints being (i) the size of the financial incentives, (ii) the extent to which the problem is solvable, and (iii) the time it might take. These propositions rest on the assumptions discussed previously in the paper, namely that SGI and SGR offer a probabilistic mechanism of knowledge creation that can transcend constraints to innovation typically associated with FGI and FGR.

On the basis of these propositions, it is argued that problems such as antibiotic resistance, microbial resistance, or other problems that are a function of knowledge (and are inherently 'soluble', or solvable) can be solved relatively quickly, as long as sufficient financial resources are invested in the process. Problems relating to biological or medical problems are considered to largely be 'finite'; this type of knowledge might be knowable, and not unknowable. The implication of this is that the solving of medical and biological problems might be uniquely suitable to this new paradigm.

Finally, it is argued that problems such as the failure of the pharmaceutical industry to solve problems such as microbial resistance and its failure to develop curative approaches to disease exist because FGI and FGR operates along a S-curve (Foster, 1985) that is offering declining results in relation to investments. This failure seems to be compounded by the incentives faced by the pharmaceutical industry (Callaghan, 2014c), a form of market failure. Curing disease would mean killing the 'golden goose' that continues to generate income as people need to keep taking medication (it needs to be paid for) their entire lives. It is understandable that such companies would be loath to find a cure if they generate billions over the life-time of patients.

In light of the above discussions, it is argued that SGI and SGR represent the next S-curve as forms of a process innovation in scientific research based on probabilistic mechanisms of knowledge creation. In conclusion, it is argued that these problems should be tackled in this way immediately. It is acknowledged that these processes are already happening, but the final argument made here is that the scale of these interventions needs to be ramped up, to the point that a nexus between social and proprietary innovation incentives is created, and the rate of problem solving can be increased, perhaps exponentially. In other words, a new paradigm in innovation can potentially exist, beyond the innovation threshold.

\section{CONCLUSION}

This paper offered the argument that innovation that does not use probabilistic mechanisms faces an innovation threshold constraint. This constraint was considered akin to the constraints faced by industries at the 'top' of an innovation S-curve (Foster, 1985); where progress has levelled off and increasing levels of investments produce diminishing returns. This paper suggests that SGI and SGR represent a new 'S-curve' in innovation, as the probabilistic mechanisms that underpin SGI and SGR differentiate this new paradigm from FGI and FGR. It was finally argued that almost any problem can be solved in radically shorter timeframes using the processes of this new paradigm, as long as these problems are inherently solvable. Biological and medical phenomena, for the most part, might perhaps be considered 'finite systems' that are inherently knowable. The overarching argument made in this paper is that attempts to solve knowable problems should be set in motion immediately; under this potential new paradigm many societal problems we face should have no reason to continue to exist. 


\section{AUTHOR INFORMATION}

Chris William Callaghan is an Associate Professor in the School of Economic and Business Sciences of the University of the Witwatersrand, South Africa. He manages the Knowledge and Information Economics/Human Resources Research Agency (KIEHRA) within the School. His research explores individual and organisational performance across different contexts, with a particular focus on how research can make a contributon to improving the lives of people through problem solving. Email: chris.callaghan@wits.ac.za

\section{REFERENCES}

1. Bienkowska, D., Larsen, K., and Sörlin, S. (2010). Public-private Innovation: Mediating roles and ICT niches of industrial research institutes. Innovation: Management, Policy \& Practice, 12(2), 206-216.

2. Bienkowska, D., Lundmark, M., and Malmberg, A. (2011). Brain circulation and flexible adjustment: labour mobility as a cluster advantage. Geografiska Annaler: Series B, Human Georgraphy, 93(1): 21-39.

3. Callaghan, C.W. (2014a). Crowdfunding to Generate Crowdsourced R\&D: The Alternative Paradigm of Societal Problem-solving Offered by Second Generation Innovation and R\&D. The Journal of Business and Economics Research, 13(6):1599-1514.

4. Callaghan, C.W. (2014b). R\&D Failure and Second Generation R\&D: New Potentialities. Mediterranean Journal of Social Sciences, 5(3), 11-24.

5. Callaghan, C.W. (2014c). A New Probabilistic Problem-Solving Paradigm: A Conceptual Critical Reflection. Mediterranean Journal of Social Sciences, 5(23), 2070-2079.

6. CDC. 2014. Centres of Disease Control and Prevention. Antibiotic/Antimicrobial Resistance. Available at: http://www.cdc.gov/drugresistance/ Accessed 26 July 2014.

7. Chesbrough, H. (2007). Why companies should have Open Business Models. MIT Sloan Management Review, 48(2), 1-22.

8. Davenport, S., Cummings, S., Daellenbach, U., \& Campbell, C. 2013. Problemsourcing: Local Open Innovation for R\&D Organizations, http://timreview.ca/sites/default/files/article_PDF/

Davenport_et_al_TIMReview_March2013.pdf, 4 July 2014.

9. David, P.A., Hall, B.H., \& Toole, A.A. (2000). Is Public R\&D a Complement or Substitute for Private R\&D? A Review of the Econometric Evidence. Research Policy, 29, 497-529.

10. Doan, A., Madhavan, J., Dhamankar, R., Domingos, P., and Halevy, A. 2003. Learning to Match Ontologies on the Semantic Web. The International Journal on Very Large Data Bases, 12(4), 303-319.

11. Doan, A., Ramakrishnan, R., \& Halevy, A.Y. (2011). Crowdsourcing Systems on the World-Wide Web. Communications of the ACM, 54(4), 86-96.

12. Finzen, J., and Kintz, M. 2012. A Comparative Study of Innovation-Related Crowdsourcing Projects in Germany. The XXIII Conference- Action for Innovation: Innovating from Experience, Barcelona, Spain, 17-20 June.

13. Foster, R. N. (1985) Timing Technological Transitions. Technology in Society, 7, 127-141.

14. González, X., \& Pazó, C. (2008). Do Public Subsidies Stimulate Private R\&D Spending? Research Policy, 37, 371-389.

15. Hall, B., \& Van Reenen, J. (2000). How effective are Fiscal Incentives for R\&D? A Review of the Evidence. Research Policy, 29, 449-469.

16. Hallerstede, S.H., \& Bullinger, A.C. 2010. Do you know where you go? A taxonomy of online innovation contests. Proceedings of the XXI ISPIM Conference.

17. Hausman, J.A., Hall, B.H., \& Griliches, Z. (1984). Econometric Models for Count Data with an Application to the Patents-R\&D Relationship. Econometrica, 52(4), 909-938.

18. Karabag, S.F., Tancay-Celikel, A., \& Berggren, C. 2011. The Limits of R\&D Internationalization and the Importance of Local Initiatives: Turkey as a Critical Case. World Development, 39(8), 1347-1357.

19. Karimi, F., and Gigova, R. 2014. WHO: Ebola outbreak in West Africa an international health emergency. CNN Health. Available at: http://www.cnn.com/2014/08/08/health/ebola-outbreak/index.html (Accessed 9 August 2014)

20. Malone, T.W., Crowston, K., Lee, J., Pentland, B., Dellarocas, C., Wyner, G., Quimby, J., Osborn, C.S., Bernstein, A., Herman, G., Klein, M., \& O’Donnell, E. (1999). Tools for Inventing Organizations: Toward a Handbook of Organizational Processes. Management Science, 45(3), 425-443. 
21. Pravitt, K. (1984). Sectoral Patterns of Technical Change. Research Policy, 343-373.

22. Salter, A.J., \& Martin, B.R. (2001) The Economic Benefits of Publically Funded Basic Research: a Critical Review. Research Policy, 509-532.

23. Terwiesch, C., \& Xu, Y. (2008). Innovation Contests, Open Innovation, and Multiagent Problem Solving. Management Science, 54(9), 1529-1543.

24. Thomke, S., \& von Hippel, E. (2002). Customers as Innovators. Harvard Business Review, 80(4), $74-81$.

25. von Hippel, E. 1994. "Sticky Information" and the Locus of Problem Solving: Implications for Innovation. Management Science, 40(4), 429-439.

26. WHO. 2014. World Health Organization. Antimicrobial Resistance. Available at: http://www.who.int/mediacentre/factsheets/fs194/en/ Accessed 26 July 2014

27. Wu, F., \& Weld, D.S. (2007). Autonomously semantifying Wikipedia. Proceedings of the sixteenth ACM Conference on Information and Technology Management, 41-50. 